\begin{tabular}{|c|c|c|}
\hline $\begin{array}{l}\text { PKS } \\
\text { PUBLIC } \\
\text { KNOWEDGE } \\
\text { PROJECT }\end{array}$ & $\begin{array}{c}\text { REVISTA DE GEOGRAFIA } \\
\text { (RECIFE) } \\
\text { http://www.revista.ufpe.br/revistageografia }\end{array}$ & $\begin{array}{l}\text { OJS } \\
\frac{\text { OPEN }}{\text { OPUNAL }} \\
\text { SYSTEMS }\end{array}$ \\
\hline
\end{tabular}

\title{
CLIMATOLOGIA DAS ONDAS DE FRIO INVERNAIS EM SANTA CATARINA - BRASIL
}

\author{
Maikon Passos Amilton Alves ${ }^{1}$, Rosando Boligon Minuzzi ${ }^{2}$ \\ ${ }^{1}$ Doutorando do Progama de Pós-Graduação em Geografia da Universidade Federal de Santa Catarina. E- \\ mail: maiconpassos@gmail.com \\ ${ }^{2}$ Professor do Departamento da Engenharia Rural da Universidade Federal de Santa Catarina. E-mail: \\ rbminuzzi@hotmail.com
}

Artigo recebido em 18/08/2017 e aceito em 15/01/2018

\begin{abstract}
RESUMO
Foi desenvolvido um estudo climatológico sobre as ondas de frio invernais em Santa Catarina, Brasil. Considerou-se onda de frio o evento em que a temperatura média diária do ar na superfície estava pelo menos duas vezes o desvio padrão abaixo do valor médio da série, naquele dia, durante dois dias consecutivos ou mais. Os resultados encontrados demonstram que as ondas de frio se distribuem de forma desigual nas regiões agroecológicas catarinenses, apresentando limiares de temperatura diferentes em sua caracterização. O mês de junho se destacou com as maiores ocorrências de ondas de frio e julho apresentou as ondas de frio mais extensas. Palavras-chave: Ondas de frio, Climatologia; Regiões Agroecológicas; Temperatura média diária do ar.
\end{abstract}

\section{CLIMATOLOGY WAVES OF COLD WINTER IN SANTA CATARINA}

\begin{abstract}
This thesis presents a climatological study on the winter cold waves in the state of Santa Catarina, Brazil.The criterion adopted for the classification of a cold wave was an event in which the mean daily air temperature at the surface was at least two standard deviations below the mean of at least two consecutive days. The standard deviation (S) is equal to the interannual mean value of the 365 daily air temperature standard deviations in a year (from January 1st to December 31st). This work only analyzes the cold waves that took place during the 92 winter days (from June 1st to August 31st). Results show that cold waves affect agroecological zones differently, with varying temperature thresholds in their characterization. The month of June was associated with the strongest cold waves, while the longest cold waves were found in July.
\end{abstract}

Keywords: cold waves; climatology; Climatology; agroecological zones; air temperature standard.

\section{INTRODUÇÃO}

A climatologia compreende de um modo geral, o estudo dos vários tipos de clima. Do ponto de vista geográfico, esta busca explicar e caracterizar tendências climáticas que ocorrem num determinado local ou região, através de um conjunto de fenômenos meteorológicos, possibilitando o conhecimento daqueles que têm influência decisiva em vários setores da sociedade, como, nas atividades humanas, sociais e econômicas. 
O Estado de Santa Catarina (Figura 1) está localizado em um local de transição entre os trópicos e as latitudes mais altas, com clima subtropical, caracterizado por apresentar distribuição regular de precipitação durante todo o ano e temperaturas que sofrem forte influência da altitude, com os menores valores registrados nos pontos de cota mais elevada (WREGE et al., 2011).

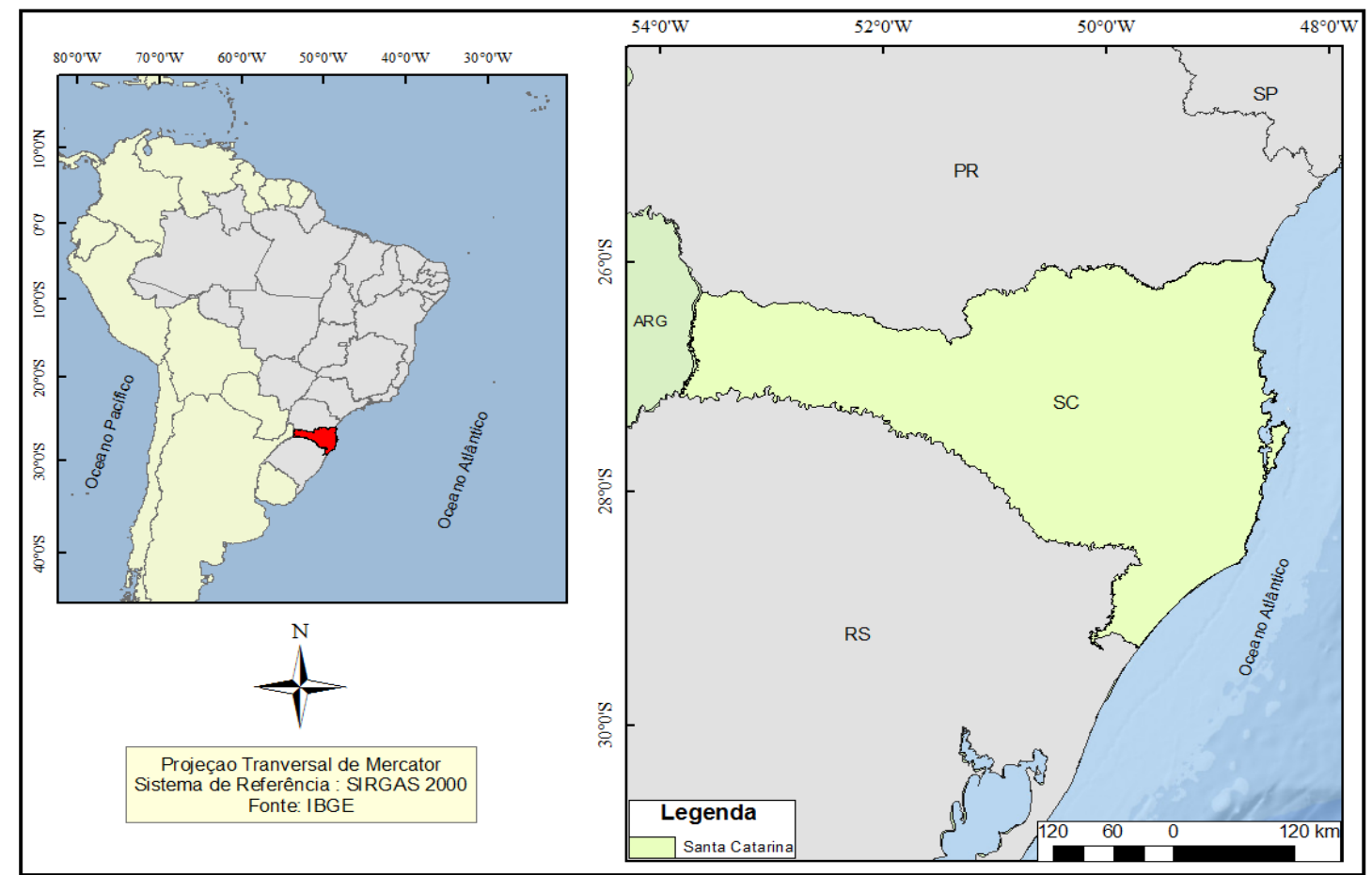

Figura 1 - Mapa de localização do estado de Santa Catarina - Elaborado por Maikon P.A.Alves.

A situação geográfica da região sul brasileira, no subtrópico, garante a maior amplitude térmica no ciclo anual, com maior diferença entre inverno e verão. As serras e o planalto meridional determinam contrastes na distribuição de temperatura, sendo esta a única região do Brasil com precipitação nival (neve), podendo registrar temperaturas consideravelmente frias (GRIMM, 2009).

No inverno austral, as condições de tempo são influenciadas pelas passagens das massas de ar polar, oriundas do continente antártico. O ar frio chega ao sul do Brasil pela aproximação dos anticiclones podendo causar acentuado declínio de temperatura em grandes porções da atmosfera, caracterizando as ondas de frio (Monteiro, 2001; Mendonça; Romero, 2012).

Não há consenso na definição de onda de frio. Encontram-se várias formas de defini-la como nos trabalhos de Boyle, (1986); Konrad, (1996); Walsh et al., (2001); Escobar, (2007); Vavrus et al., (2006); Firpo, (2008). Alguns trabalhos definem onda de frio como um evento 
específico, outros definem as ondas de frio como a queda extrema ou anômala da temperatura do ar, sem definir um limiar de temperatura e a periodicidade. No Manual de Desastres Naturais Castro et al. (1995, p.21) caracterizam uma onda de frio por um evento de rápida e grande queda na temperatura, sobre uma extensa área, permanecendo por várias horas, dias e, por vezes, uma semana ou mais. Ainda segundo Castro (1995) na América do Sul as ondas de frio são mais recorrentes entre os meses de maio e setembro, com predominância nos meses invernais, julho e agosto, e normalmente os episódios duram de quatro a cinco dias.

Para Vavrus et al. (2006) um extremo de frio é definido como uma ocorrência de dois dias ou mais consecutivos, durante o qual a temperatura média diária do ar na superfície, é pelo menos duas vezes o desvio padrão abaixo da temperatura média do local de inverno.

Mendonça e Romero (2012) ao estudarem os impactos socioambientais das ondas de frio, associadas aos índices de oscilação das variabilidades de baixa frequência na América do Sul, constataram que as ondas de frio intercontinentais por vezes provocam enfermidades e mortes de pessoas e perdas econômicas, o que acaba impactando o desenvolvimento das atividades na cidade e no campo, danificando paisagens e culturas em diversos países da América do Sul.

O frio tem sido subestimado como um desastre socionatural, pois nem toda a população é atingida igualmente, e as atividades urbanas de comércio e serviços muitas vezes se beneficiam das quedas de temperatura. $\mathrm{O}$ frio, entretanto, ao atingir populações carentes, pode significar exigências sobre serviços de saúde e assistência social, o que deveria mobilizar as instituições governamentais para também se planejarem quanto à sazonalidade do frio e suas variabilidades, visando atender através de políticas públicas, as populações mais vulneráveis.

Dessa forma, conhecer a variabilidade das ondas de frio pode auxiliar no melhor entendimento do clima da região Sul, especialmente do estado catarinense, tendo em vista a dependência econômica do Estado em relação às atividades agrícolas, pecuária, industrial e a vocação turística. Estas atividades para que tenham êxito necessitam de condições climáticas favoráveis ou de planejamento para o enfrentamento das adversidades.

Nesse sentido este trabalho teve como objetivo principal identificar e analisar as ondas de frio em Santa Catarina no período de 1983 a 2013, durante o período de inverno. 


\section{MATERIAIS E MÉTODOS}

\section{Dados de temperatura}

Foram utilizados dados de temperatura média do ar diária de 11 estações meteorológicas convencionais (Figura 2) pertencentes à Empresa de Pesquisa Agropecuária e Extensão Rural de Santa Catarina/Centro de Informações Ambientais e de Hidrometeorologia (Epagri/Ciram) e Instituto Nacional de Meteorologia (INMET). A série temporal de dados de temperatura média do ar diária, medida em graus Celsius $\left(C^{\circ}\right)$, compreende os anos de 1983 a 2013, no período invernal, totalizando 31 anos de dados.

Optou-se por não utilizar a temperatura mínima na identificação das ondas de frio como algumas pesquisas sugerem (Konrad, 1996; Walsh et al., 2001; Escobar, 2007; Firpo, 2008) tendo como justificativa a amplitude térmica que algumas regiões podem apresentar. Por exemplo, em um determinado município a temperatura mínima registrada pode ser de $2{ }^{\circ} \mathrm{C}$ às 6 horas, no entanto, em boa parte do dia registram-se temperaturas elevadas em torno de $22^{\circ} \mathrm{C}$, ou seja, na maior parte do tempo em que as pessoas estão expostas ao ambiente por seus afazeres cotidianos, a temperatura não é realmente tão baixa quanto em um dia que registra temperatura média diária do ar de $2^{\circ} \mathrm{C}$.

Os registros de geada também foram cedidos pela Epagri/Ciram. Para efeito de regionalização utilizou-se a divisão delimitada pelas Zonas Agroecológicas de Santa Catarina, que entre outros fatores considera as regiões climaticamente homogêneas do estado de acordo com Thomé et al. (1999). 


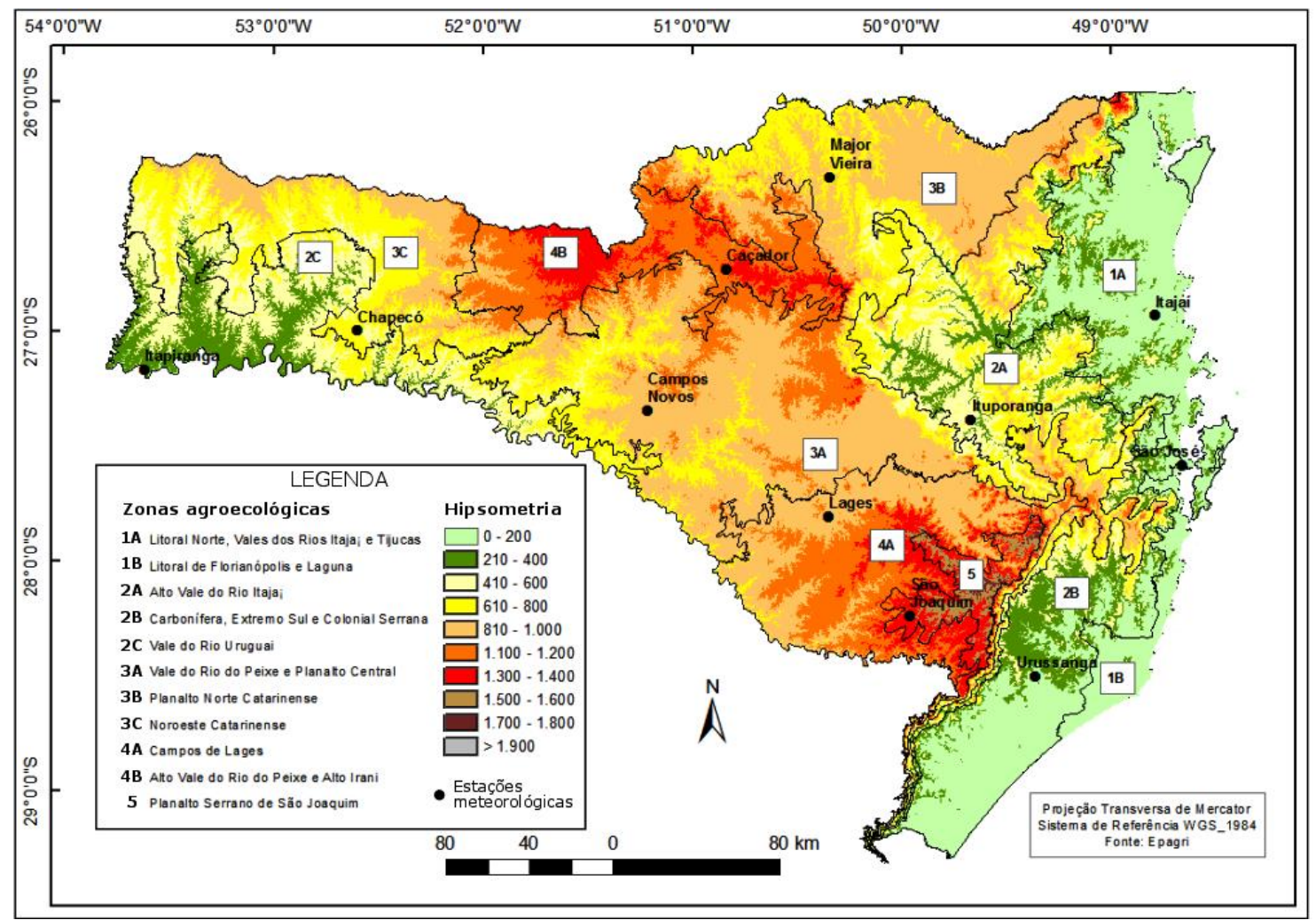

Figura 2 - Mapa hipsométrico do estado de Santa Catarina com a localização das estações meteorológicas e suas respectivas zonas agroecológicas. Elaborado por Maikon P. A. Alves.

\section{Identificação das ondas de frio}

Os dados de temperatura média do ar compensada foram tabulados via programa Excel 2007 e então o método para classificação das ondas de frio de Vavrus et al. (2006) foi aplicado. Este método considera como onda de frio o evento no qual a temperatura média diária do ar na superfície esta pelo menos duas vezes o desvio padrão abaixo do valor da média durante dois dias consecutivos ou mais, no período invernal. O desvio padrão (S) é o valor médio dos 365 desvios padrões diário de temperatura do ar. Todavia, este trabalho trata apenas dos 92 dias do período de inverno ( $1^{\circ}$ de junho a 31 de agosto).

Em outras palavras, para identificação das ondas de frio, verificou-se a média da temperatura média diária de todos os dias do ano, entre 1983 e 2013 (Equação 1).

$$
\overline{T m}=\frac{\sum_{i=1}^{n} T m_{i}}{n}
$$

Onde: $\overline{T m}=$ média das temperaturas médias diárias, $\mathrm{Tm}_{\mathrm{i}}=$ temperatura média diária.

Após isso se estabeleceu o desvio padrão de cada dia (Equação 2). 


$$
S=\sqrt{\frac{\sum_{i}^{n}\left(T m_{i}-T m\right)^{2}}{n-1}}
$$

Onde: $\mathrm{S}$ = desvio padrão da temperatura média diária.

Posteriormente foi calculada a média de todos os desvios padrão diários (Equação 3).

$$
\bar{S}=\frac{\sum_{i=1}^{n} s_{i}}{n}
$$

Onde: $\bar{s}=$ média de todos os desvios padrões diários.

Por último calculou-se a média diária de todos os dias individualmente menos duas vezes o desvio padrão geral encontrado (Equação 1), estabelecendo o limiar diário específico para cada dia do ano. Sendo assim, é classificado como dia frio, aquele que registrar a temperatura média do ar abaixo ou igual o limiar identificado para sua data (Equação 4).

$$
T m_{i} \leq(2 \times \bar{S})
$$

Onde: $T m_{\mathrm{i}}=$ temperatura média diária, $\bar{s}=$ média de todos os desvios padrões diários.

Conforme Vavrus et al. (2006) esta definição de onda de frio identifica apenas ondas extremas; mesmo assim, pode fornecer uma quantidade razoavelmente grande de eventos extremos.

Sendo assim, é classificado como dia frio, aquele dia que registrar a temperatura média do ar abaixo ou igual ao limiar identificado para sua data e; para ser classificada como onda de frio é necessário que isso ocorra por dois dias consecutivos ou mais.

\section{RESULTADOS E DISCUSSÕES}

\section{Comportamento geral das ondas de frio}

Em todos os invernos analisados ocorreram onda de frio em pelo menos uma das onze estações avaliadas. Foram encontradas 131 ondas de frio, média de 4,22 eventos por ano/invernal. Analisando a Figura 3, os anos em que ocorreram maior número de ondas de frio foram 1993 (11 ocorrências), seguidos de 1990 (7 ocorrências). Já 1986, 1989 e 1998 foram os anos que tiveram os invernos com a atuação de apenas 1 evento de onda de frio. 


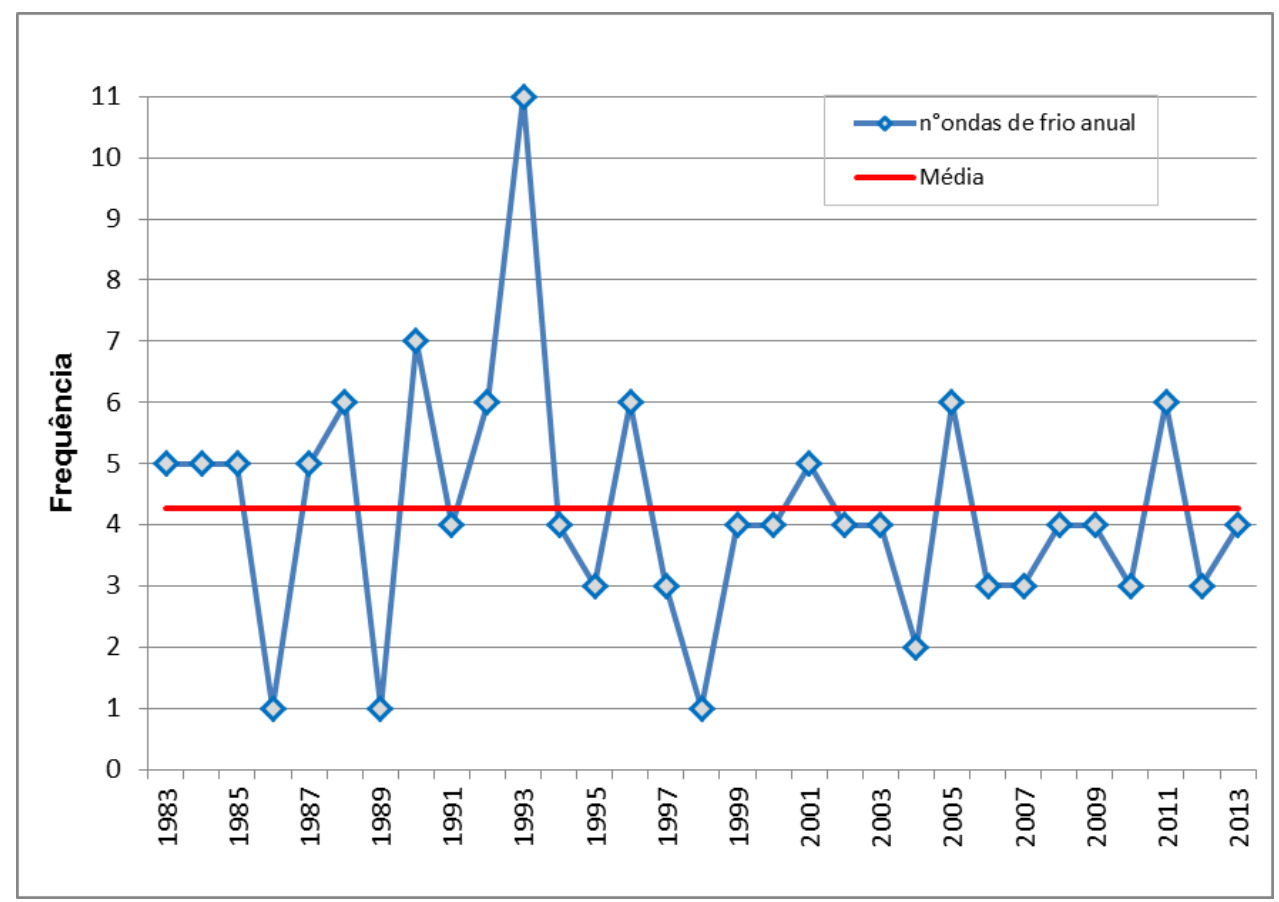

Figura 3 - Frequência anual das ondas de frio invernais em Santa Catarina, entre 1983 a 2013. Fonte: Elaborado pelos autores.

A Figura 4 aborda a análise mensal das ondas de frio encontradas. Observa-se que 48 (36,6\%) ocorreram no mês de junho, 47 (35,9\%) em agosto e 36 (27,5\%) no mês de julho, resultado semelhante ao traballho de Firpo (2008) que ao investigar a climatologia das ondas de frio para o Estado do Rio Grande do Sul, verificou o mês de junho como o de maior ocorrência, seguido por agosto e julho.

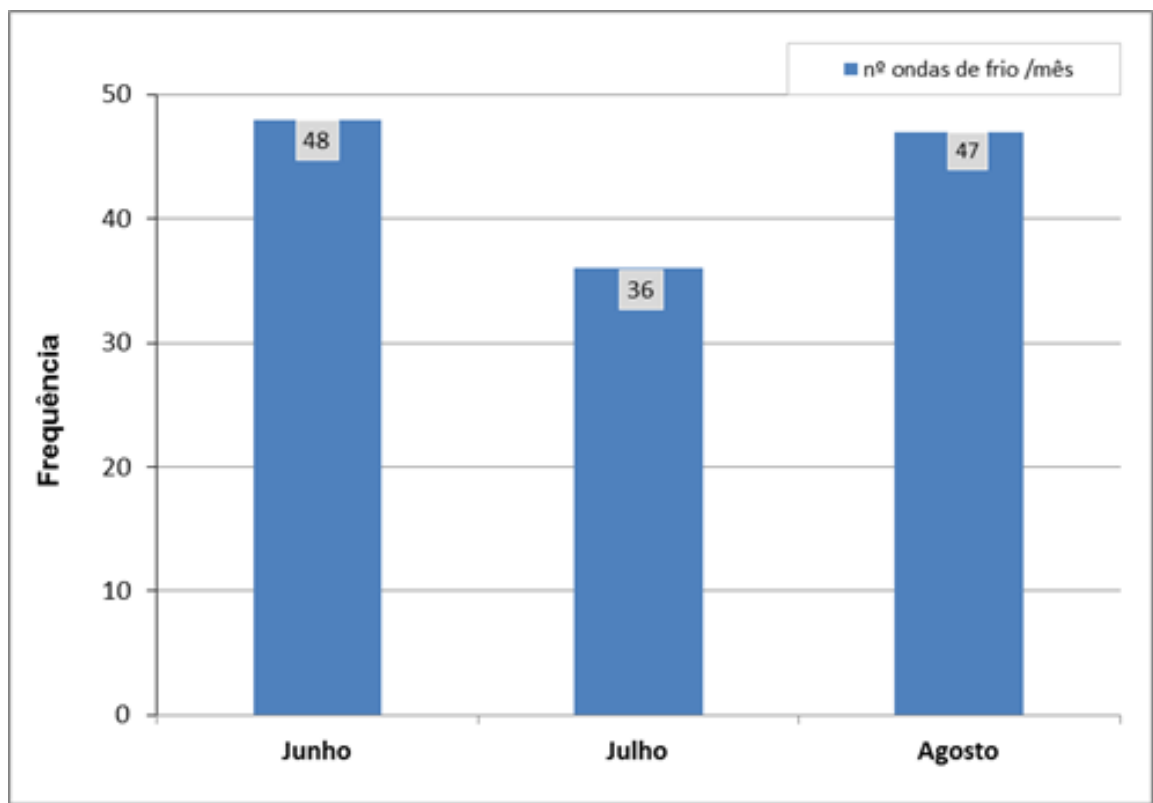

Figura 4 - Ocorrência mensal de onda de frio em Santa Catarina no periodo invernal de 1983 a 2013. Fonte: Elaborado pelos autores. 
A onda de julho de 2000 entre os dias 12 a 20 foi a de maior extensão temporal ( 9 dias); na sequência a de julho de 2011 ( 2 a 9) que atuou por 8 dias e a ondas de frio de junho de 1987 (15 a 20) e junho de 1994 (24 a 29) durando 6 dias (Tabela 1).

Além dos fatores geográficos como latitude, relevo, altitude, continentalidade e maritimidade, que acabam influenciando as temperaturas no estado (AGUIAR; MENDONÇA, 2004) há também o impacto das variações nos padrões atmosféricos, como as variabilidades climáticas de baixa frequência (VBF), na escala interanual o El Niño-Oscilação Sul (ENOS), Oscilação Antártica (AAO) na escala sazonal e na escala decadal a Oscilação Decadal do Pacífico (ODP). Segundo Alves (2016), em seu trabalho intitulado: Ondas de frio invernais em Santa Catarina e suas relações com as Variabilidades de baixa frequência, os anos com maiores registros de ondas de frio, e as ondas de maior abrangência temporal estiveram atrelados as VBF: apontando que a Oscilação Antártica em sua fase positiva possui maior recorrência nos anos de maior registro de ondas de frio; já a atuação conjunta da fase fria da ODP e a La Niña, contribuem para as ondas de frio de maior escala temporal. O que pode está atrelado ao que Kayano e Andreoli (2007) denominam de efeito construtivo, quando o ENOS e a ODP estão na mesma fase, e destrutivo quando eles estão em fases oposta. Podendo significar que em anos de La Niña e fase fria de ODP, o padrão de anomalia negativa da temperatura seja mais evidente do que quando ocorre El Niño e fase fria da ODP ou ainda La Niña e a fase quente da ODP (MENDONÇA; ROMERO, 2012). 
Tabela 1 - Ondas de frio com maior abrangência temporal em SC (1983 a 2013).

\begin{tabular}{cccc}
\hline \multicolumn{4}{c}{ Abrangência temporal das ondas de frio } \\
\hline Ano & Mês & Intervalo & $\mathbf{N}^{\circ}$ de dias \\
1987 & Junho & 15 a 20 & 6 \\
1989 & Julho & 5 a 9 & 5 \\
\hline & Julho & 20 a 23 & 4 \\
1990 & Agosto & 28 a 30 & 3 \\
\hline 1991 & Agosto & 1 a 4 & 4 \\
1993 & Julho & 30 a $02 / 08$ & 4 \\
1994 & Junho & 24 a 29 & 6 \\
& Julho & 8 a 11 & 4 \\
\hline 1999 & Agosto & 13 a 16 & 4 \\
\hline 2000 & Julho & 12 a 20 & 9 \\
& Julho & 23 a 27 & 5 \\
\hline 2004 & Junho & 12 a 14 & 3 \\
\hline 2006 & Agosto & 19 a 21 & 3 \\
\hline 2007 & Julho & 25 a 29 & 5 \\
\hline 2008 & Junho & 15 a 18 & 4 \\
\hline 2011 & Julho & 2 a 9 & 8 \\
\hline 2013 & Julho & 21 a 25 & 5 \\
\hline \multicolumn{4}{c}{ Fonte: Elaborado pelos autores. }
\end{tabular}

Distribuição espaço-temporal das ondas de frio por estação meteorológica (Zona Agroecológica)

Durante os 31 invernos analisados (1983 a 2013) observa-se que as ocorrências das ondas de frio se distribuíram de forma desigual nas regiões agroecológicas catarinenses (Figura 5). As estações de Chapecó e Caçador apresentaram maior número de ocorrência, 93 e 77, respectivamente, seguidas por Campos Novos (71); São Joaquim (69); Lages (64); Itajaí (58); Ituporanga 56; Urussanga (54); São José (52); Major Vieira (50) e Itapiranga (48). A média de ocorrência foi de $(62,8)$ ondas de frio nas onze estações de Santa Catarina, no período de 1983 a 2013. Ressalta-se que algumas estações possuem período de dados distintos: Itapiranga (1987 a 2013); Major Vieira (1988 a 2013) e as estações de São Joaquim e Ituporanga (1984 a 2013).

De modo geral as regiões com altitudes elevadas apresentaram maior número de ocorrência de onda de frio, salientando a influência do relevo e altitude no comportamento da temperatura no Estado. Outro fato importante que pode justificar essa distribuição espacial das ondas de frio são as trajetórias sazonais dos sistemas polares, que em seu deslocamento mais continental, acabam por penetrarem pela região mais a oeste/sudoeste do Estado. Em Santa Catarina, a continentalidade, o relevo, a altitude e a maritimidade são os fatores que 
possuem maior interação com os sistemas atmosféricos, portanto, são os mais influentes (MONTEIRO; MENDONÇA, 2014, p.5).

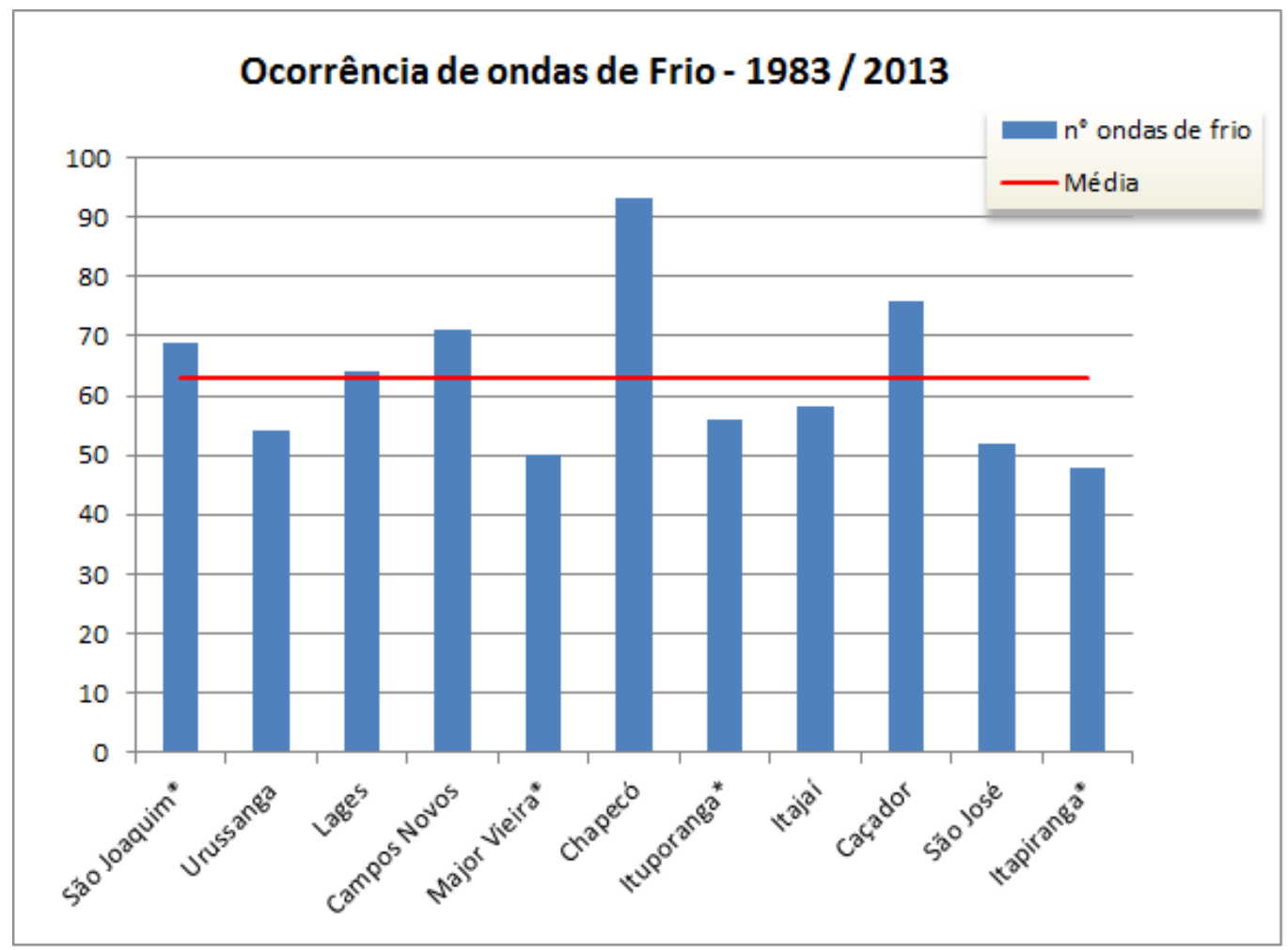

Figura 5 - Número de ocorrência das ondas de frio invernais em Santa Catarina entre 1983 -2013. Nota: (*) Estações com menores séries de dados. Fonte: Elaborado pelo autor.

Estes resultados são de grande valia para o setor agrícola, e consequentemente, para a economia e sociedade do Estado, que ostenta o primeiro lugar na produção nacional de culturas como a maçã e a cebola (IBGE, 2016). Como exemplos, as baixas temperaturas do outono e inverno, desde que, não congelantes, são essenciais para a quebra da dormência das gemas florais e vegetativas de fruteiras de clima temperado, como para a maçã (PEREIRA; ANGELOCCI; SENTELHAS, 2002), cultivada principalmente, nas regiões de São Joaquim e Caçador.

Já a cebola, Oliveira; Marouelli e Madeira (2009) destacam que apesar de ser originária de regiões de clima temperado, não tolera frio muito intenso ou prolongado, onde em casos extremos, resulta na queima de folhas, além do que, temperatura do ar abaixo de $6^{\circ} \mathrm{C}$, cessa o crescimento foliar da planta que é cultivada predominantemente na região de Ituporanga.

A saúde é outro setor impactado nos episódios extremos de temperatura como as ondas de frio. No caso dos problemas de saúde respiratórios e circulatórios, as ondas de frio podem 
operar como potencializadores dos problemas de saúde, todavia, outras variáveis condicionantes podem existir, como, por exemplo: má alimentação, habitações inadequadas, falta de acesso aos serviços de saúde, ser fumante ou não, falta de exercícios físicos e outros problemas de saúde pré-existentes (MURARA, 2012). A exposição a temperaturas baixas pode resultar em inúmeras consequências negativas para a saúde, podendo levar a morte. Os danos provocados pelas ondas de frio estão mais diretamente relacionados com a vulnerabilidade de determinadas populações, do que com a magnitude do evento (CASTRO, 2003). As populações mais vulneráveis são constituídas por idosos, enfermos, crianças e animais de rua, principalmente quando estes, são pertencentes a populações de baixa renda, ou quando desabrigados e desprovidos de agasalhos.

Em Santa Catarina, alguns estudos demostram esta relação do frio com as enfermidades, desde as regiões mais elevadas do estado as litorâneas. Silveira et al. (2014) ao analisarem o frio com as doenças respiratórios no município de Biguaçu (litoral), observaram que no inverno aumentam as internações por influenza, asma e pneumonia em relação às outras estações do ano. Em São Joaquim, região serrana catarinense, Silveira (2016) aponta que durante os episódios de ondas de frio considerando todos os dias do ano, as doenças respiratórias são mais expressivas do que as circulatórias, especialmente entre o sexo feminino. As enfermidades do aparelho circulatório atingem mais aos idosos e mulheres, especialmente nos casos de infarto do miocárdio. Nas respiratórias o grupo etário mais atingido foi o dos jovens, principalmente diante da asma, afetando mais ao sexo masculino. Notou-se que os grupos mais vulneráveis são de fato aqueles que a bibliografia aponta como sendo os de menor autonomia, ou seja, os jovens e os idosos (SILVEIRA, 2016).

A Figura 6, onde é exposto à variabilidade média das ondas de frio em Santa Catarina por estações, nota-se certa heterogeneidade dos valores para a maioria destas. As estações que apresentaram as maiores médias anuais de ondas de frio foram: Caçador, São Joaquim, Campos Novos e Chapecó, que variaram entre 2,1 a 3 eventos ao ano. Já as estações que registraram menor incidência de ondas de frio (entre 1,7 a 1,8) foram São José, Urussanga, Itajaí e Itapiranga. Nesta distribuição influem além das trajetórias sazonais dos sistemas polares, também os fatores geográficos. A presença de uma área litorânea em concomitância com uma região continental exerce grande influência nas temperaturas, gerando regiões agroecológicas diversificadas. A altitude, devido aos distintos relevos e a exposição de vertente que o Estado apresenta, ocorrendo uma variabilidade muito grande de região para região. 


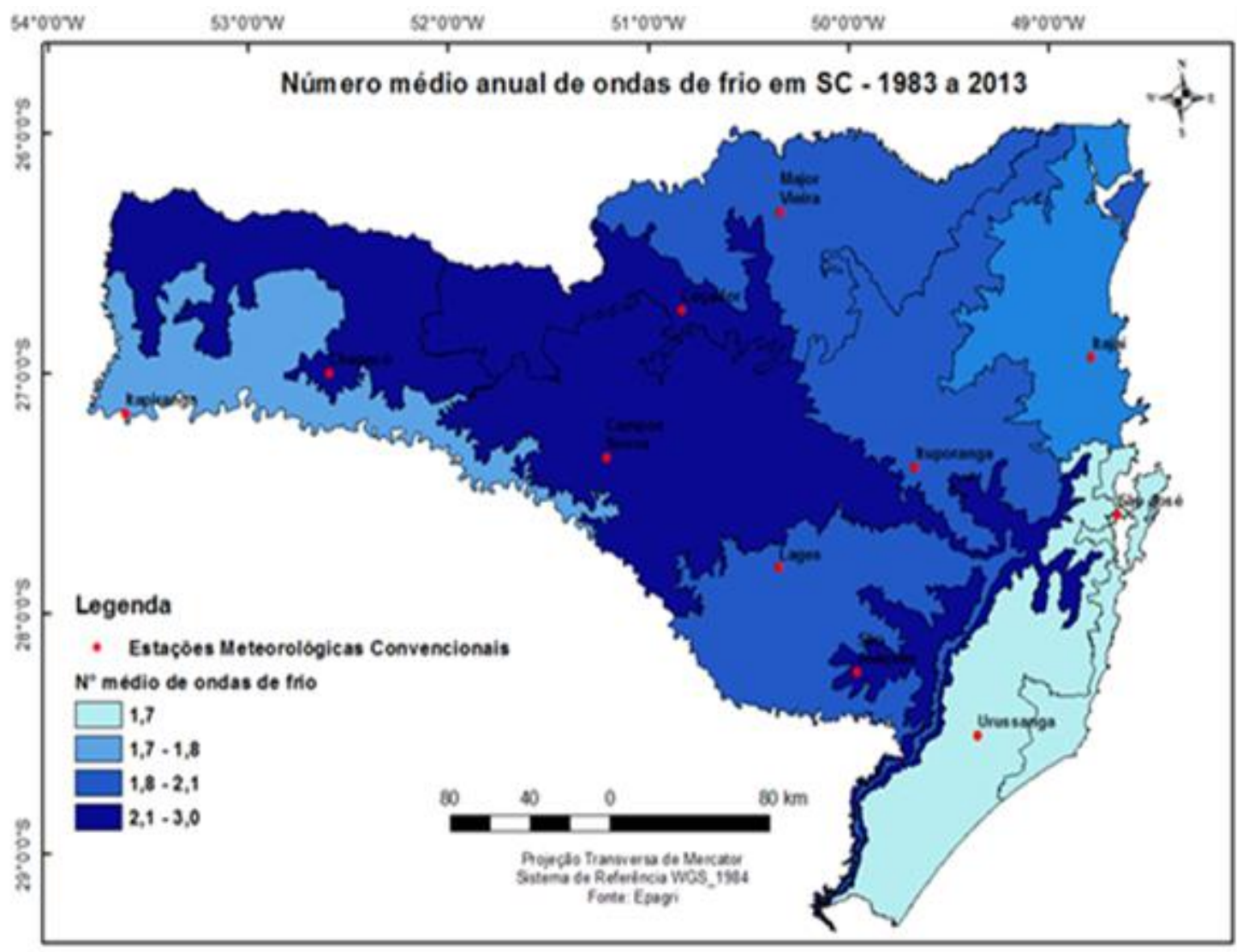

Figura 6- Mapa de frequência média anual de ondas de frio por estações, para Santa Catarina, no período de 1983-2013. Fonte: Elaborado pelo autor.

Considerando as informações da Tabela 2, observa-se que em média 51,4\% das ondas de frio registradas abrangeram dois dias, número mínimo de dias para se considerar uma onda, de acordo com o critério adotado neste estudo; $30,7 \%$ foram de três dias consecutivos; $9,7 \%$ de 4 dias; $5,5 \%$ com 5 dias e o restante divididos entre 6, 7,8 e 9 dias consecutivos. 
Tabela 2 - Porcentagem da duração das ondas de frio em Santa Catarina por região agroecológica, no período de 1983 a 2013

\begin{tabular}{|c|c|c|c|c|c|c|c|c|c|}
\hline \multirow{3}{*}{$\begin{array}{c}\text { Estações } \\
\text { Meteorológicas/Regiões } \\
\text { Agroecológicas }\end{array}$} & \multicolumn{9}{|c|}{ Número de dias consecutivos } \\
\hline & 2 & 3 & 4 & 5 & 6 & 7 & 8 & 9 & total \\
\hline & \multicolumn{9}{|c|}{$\%$} \\
\hline Itajaí (1A) & 44,9 & 29,3 & 15,5 & 6,9 & 1,7 & 1,7 & 0 & 0 & 100 \\
\hline São José (1B) & 53,8 & 28,8 & 9,6 & 5,8 & 1,9 & 0,0 & 0,0 & 0,0 & 100 \\
\hline Ituporanga (2A) & 48,2 & 35,7 & 7,1 & 7,1 & 1,8 & 0,0 & 0,0 & 0,0 & 100 \\
\hline Urussanga (2B) & 53,7 & 29,6 & 9,3 & 1,9 & 3,7 & 0,0 & 1,9 & 0,0 & 100 \\
\hline Itapiranga (2C) & 43,8 & 35,4 & 12,5 & 2,1 & 4,2 & 2,1 & 0,0 & 0,0 & 100 \\
\hline Campos Novos (3A) & 57,7 & 25,4 & 11,3 & 2,8 & 1,4 & 0,0 & 0,0 & 1,4 & 100 \\
\hline Major Vieira (3B) & 52,0 & 34,0 & 6,0 & 6,0 & 0,0 & 2,0 & 0,0 & 0,0 & 100 \\
\hline Chapecó (3C) & 54,8 & 26,9 & 10,8 & 7,5 & 0,0 & 0,0 & 0,0 & 0,0 & 100 \\
\hline Lages (4A) & 53,1 & 31,3 & 9,4 & 3,1 & 3,1 & 0,0 & 0,0 & 0,0 & 100 \\
\hline Caçador (4B) & 48,1 & 33,8 & 5,2 & 11,7 & 1,3 & 0,0 & 0,0 & 0,0 & 100 \\
\hline São Joaquim (5) & 55,1 & 27,5 & 10,1 & 5,8 & 1,4 & 0,0 & 0,0 & 0,0 & 100 \\
\hline Média & 51,4 & 30,7 & 9,7 & 5,5 & 1,9 & 0,5 & 0,2 & 0,1 & 100 \\
\hline
\end{tabular}

Fonte: Elaborado pelo autor.

\section{CONSIDERAÇÕES FINAIS}

As ondas de frio se distribuem de forma desigual nas regiões agroecológicas catarinenses, devido aos fatores geográficos, a variabilidade dos sistemas meteorológicos e as trajetórias dos sistemas polares, no inverno mais continental. As estações de Chapecó, Caçador, Campos Novos e São Joaquim apresentaram maior número de ocorrências de ondas de frio no inverno em Santa Catarina.

Foram identificadas ao longo de 1983 a 2013, 131 ondas de frio no Estado de Santa Catarina, em que 83,3\% dos casos ocorreram de 3 a 6 ondas de frio por ano. O mês de junho se destacou como o que teve o maior número (48) de ocorrência de ondas de frio. Já julho apresentou as ondas de frio mais extensas. Aproximadamente $82,1 \%$ das ondas de frio registradas abrangeram entre $2(51,4 \%)$ e $3(30,7 \%)$ dias de duração.

\section{AGRADECIMENTOS}

Os autores agradecem a Epagri/Ciram e ao INMET pelo fornecimento dos dados meteorológicos utilizados na pesquisa. Ao Programa de Pós-Graduação em Geografia - PPGG da UFSC, berço desta pesquisa por meio de uma dissertação já concluída. 


\section{REFERÊNCIAS}

ALVES, M.P.A. Ondas de frio invernais em Santa Catarina e suas relações com as variabilidades climáticas de baixa frequência. Dissertação (Mestrado em Geografia) Departamento de Geociências, Centro de Filosofia e Ciências Humanas, Universidade Federal de Santa Catarina. Florianópolis, 158 p.; 2016.

AGUIAR, D. MENDONÇA, M. Climatologia das geadas em Santa Catarina. In: SIMPÓSIO BRASILEIRO DE DESASTRES NATURAIS, 1., 2004, Florianópolis: GEDN/UFSC,2004. p. $762-773$ (CD-ROM).

BOYLE, J. S. Comparison of the synoptic conditions in midlatitudes accompanying cold surges over eastern Asia for the months of December 1974 and 1978. Part I: Monthly mean fields and individual events. Monthly Weather Review, n. 114 p. 903-930, 1986.

CASTRO, A.L.C.; CALHEIROS, L.B.; CUNHA, M.I.R.; BRINGEL, M.L.N.C. Manual de desastres naturais. Ministério do Planejamento e Orçamento, Secretaria Especial - Defesa Civil. Novembro, v. 1, 1995.

CASTRO, A.L.C.; CALHEIROS, L.B.; CUNHA, M.I.R; BRINGEL, M.L.N.C. Manual de Desastres - Desastres Naturais. Ministério da Integração Nacional - MI, Brasília, v. 1, 2003.

ESCOBAR. G. Padrões Sinóticos Associados a Ondas de Frio na Cidade de São Paulo. Revista Brasileira de Meteorologia, v.22, n.2, 241-254, 2007.

FIRPO, M.A.F. Climatologia das ondas de frio e calor para o Rio Grande do Sul e sua Relação com o El Niño e La Niña. Dissertação apresentada de Pós-Graduação da Faculdade e Meteorologia da Universidade Federal de Pelotas. Pelotas, 2008.120p.

GRIMM, A. M. Variabilidade Interanual do Clima no Brasil. In: CAVALCANTI, I.F.A. et al (org). Tempo e Clima no Brasil. São Paulo: Oficina de texto, 2009.

INSTITUTO BRASILEIRO DE GEOGRAFIA E ESTATÍSTICA - IBGE. Banco de dados agregados - Agricultura. Acesso em: <http:// http://www.sidra.ibge.gov.br>. Acesso em: 01 nov. 2016. 
KAYANO, M. T.; ANDREOLI, R. V. Relation of South American summer rainfall interanual variations with the Pacific Decadal Oscillation. Int. J. Climatology, v.27, n.4, p.531-540, 2007.

KONRAD, C. E. Relationships between the intensity of cold-air outbreaks and the evolution of synoptic and planetary-scale features over North America. Monthly Weather Review, n. 124 p. 1067-1083, 1996.

MENDONÇA, M.; ROMERO, H. ondas de frio, índices de oscilação e impactos socioambientais das variabilidades climáticas de baixa frequência na América do sul. Edição Especial - "Climatologia Geográfica”, Revista Acta Geográfica (UFRR), v.2, p.185 - 185, 2012.

MONTEIRO, M Caracterização climática do estado de Santa Catarina: uma abordagem dos principais sistemas atmosféricos que atuam durante o ano. Geosul. Revista do Departamento de Geociências da UFSC, Florianópolis, v. 16, nº 31, p 69-78. 2001.

MONTEIRO, M.; MENDONÇA, M. Dinâmica Atmosférica no Estado de Santa Catarina. In: HERMANN, M. L. P. (org). Atlas de Desastres Naturais do Estado de Santa Catarina: Período de 1980 a 2010. 2 ed. Florianópolis: IHGSC, GCN/UFSC. 2014, 217 p.

MURARA, P. G. Variabilidade climática e doenças circulatórias e respiratórias em Florianópolis (SC): uma contribuição à climatologia médica. Dissertação (mestrado em Geografia) - Departamento de Geociências, Centro de Filosofia e Ciências Humanas, Universidade Federal de Santa Catarina, Florianópolis, 94 p., 2012.

OLIVEIRA, V.R.; MAROUELLII, W.A.; MADEIRA, N.R. Cebola. In: MONTEIRO, J.E.B.A. Agrometeorologia dos cultivos: o fator meteorológico na produção agrícola. Brasília: INMET, 2009. p.151-165.

PEREIRA, A.R.; ANGELOCCI, L.R.; SENTELHAS, P.C. Agrometeorologia: Fundamentos e aplicações práticas. Guaíba, RS: Agropecuária, 2002. 478p.

SILVEIRA, R.B.; ALVES, M.P.A.; MENDONÇA, M. O frio como desastre socionatural e a sua relação com doenças vinculadas ao aparelho respiratório no município de Biguaçu e na microbacia São Mateus - Santa Catarina - Brasil. In: Anais do VIII Simpósio 
Latinoamericano de Geografia Física e IV Simpósio Iberoamericano de Geografia Física, Santiago do Chile, p.1218-1226, 2014.

SILVEIRA, R.B. Ondas de frio em São Joaquim - Santa Catarina - Brasil: a saúde como fator dependente da qualidade de vida. Dissertação (Mestrado em Geografia) Departamento de Geociências, Centro de Filosofia e Ciências Humanas, Universidade Federal de Santa Catarina. Florianópolis, 172 p., 2016.

THOMÉ, V. M. R. et al. Zoneamento agroecológico e socioeconômico do Estado de Santa Catarina. Florianópolis: Epagri, 1999. CD-ROM.

VAVRUS, S.; WALSH, J. E.; CHAPMAN, W. L.; PORTIS, D. The behavior of extreme cold air outbreaks under greenhouse warming. Int. J. Climatol., n. 26, p. 1133-1147, 2006.

WALSH, J. E.; PHILliPS, A. S.; PORTIS, D. H.; CHAPMAN, W. L. Extreme cold outbreaks in the United States and Europe, 1948-99. Journal of Climate, n. 14, p. 2642$2658,2001$.

WREGE, M. S. et al. Átlas Climático da Região Sul do Brasil: Estados do Paraná, Santa Catarina e Rio Grande do Sul. 21 ${ }^{\text {a }}$ ed. Pelotas: Embrapa, 2011. 331p. 